\title{
AVALIAÇÃO DE DIFERENTES FONTES PROTÉICAS SOBRE O DESEMPENHO INICIAL DE LARVAS DO JUNDIÁ Rhamdia quelen ${ }^{1}$
}

\author{
EVALUATION OF DIFFERENT SOURCES OF PROTEIN ON THE INITIAL PERFORMANCE \\ OF SOUTH AMERICAN CATFISH LARVAE Rhamdia quelen
}

\author{
Rosamari Piaia $^{2}$ João Radünz Neto ${ }^{3}$
}

RESUMO

\begin{abstract}
O presente estudo foi realizado com o objetivo de avaliar o efeito de diferentes fontes protéicas sobre a sobrevivência e crescimento de larvas de Rhamdia quelen durante as três primeiras semanas de vida. Utilizou-se 3000 larvas distribuídas em 15 grupos, estocadas em condições controladas de cultivo, em um sistema de criação com reutilização de água, termoregulada. As rações testadas eram isoprotéicas com $35 \%$ de PB (proteína bruta) e níveis energéticos variando entre 3075 e $3286 \mathrm{kcal} \mathrm{ED/kg}$, formuladas com fontes de origem animal, vegetal e pó de levedura Saccharomyces cerevisae. A granulometria dos alimentos testados foi de 100 a 200 $\mu, 200$ a $400 \mu$ e 400 a $600 \mu$ para as três semanas experimentais, respectivamente. A distribuição do alimento foi feita à vontade entre 8 e 20 horas. No final deste experimento o tratamento T1, contendo fígado bovino e levedura, resultou na maior taxa de sobrevivência (61\%) apresentando diferença altamente significativa em relação aos demais tratamentos. Os tratamentos 2 (soja, levedura), 3 (soja, fígado bovino), 4 (soja, milho) e 5 (soja, carne, milho) não diferiram significativamente entre si, apresentando baixas taxas de sobrevivência $(1,17$ a 10,19\%). O T1 apresentou o maior comprimento total aos 21 dias, com média individual de 16,46mm, diferindo significativamente dos demais tratamentos. Nestas condições conclui-se que o pó de levedura juntamente com o fígado bovino em rações, proporcionou o melhor desempenho de larvas de jundiá Rhamdia quelen.
\end{abstract}

Palavras-chave: dieta, farelo de soja, fígado, levedura, peixe. SUMMARY

The experiment was carried out to evaluate the survival and growth of catfish larvae Rhamdia quelen with different sources of protein during the first three weeks of life. Five treatments, with three replications, were tested. A total of 3000 larvae were randomly distributed into 15 groups, maintained under controlled conditions using a termoregulatory water re-use system. The artificial diets tested contained $35 \%$ of crude protein and digestible energy varied from 3075 to $3286 \mathrm{kcal} / \mathrm{kg}$ of dry matter. Granulometry of the ration was 100 to $200 \mu, 200$ to $400 \mu$ and 400 to $600 \mu$ during the first, second and third week, respectively. The diets were offered ad libitum from 8 am to $8 \mathrm{pm}$. The treatment 1 , containig bovine liver and yeast (Saccharomyces cerevisae), resulted in the highest $(P<$ $0.05)$ survival rate $(61 \%)$. The remaining treatments: 2 (soybean, yeast), 3 (soybean, bovine liver), 4 (soybean, corn) and 5 (soybean, meat, corn) did not differ significantly among each other, resulting in low survival rates (1.17 to $10.19 \%)$. Larvae of $T 1$ were significantly longer $(16.46 \mathrm{~mm})$ at 21 days of age than the others. It can be concluded that feeding ration containing bovine liver plus yeast results in could be a good performance of catfish larvae.

Key words: diet, growth, liver, soybean meal, survival.

\footnotetext{
${ }^{1}$ Extraído da dissertação apresentada pelo primeiro autor para obtenção do grau de mestre em Zootecnia na Universidade Federal de Santa Maria (UFSM)

${ }^{2}$ Bióloga, Mestre em Zootecnia.

${ }^{3}$ Engenheiro Agrônomo, Doutor, Professor Adjunto, Deparamento de Zootecnia, UFSM, Camobi, 97119-900 Santa Maria, RS. Autor para correspondência.
} 


\section{INTRODUÇÃO}

O jundiá Rhamdia quelen, pertencente à família Pimelodidae, é uma espécie nativa do Brasil, e muito aceito para o consumo humano pela qualidade de sua carne. É rústico, de manejo relativamente fácil e responde muito bem à reprodução induzida com fecundidade elevada (ANDREATTA, 1979).

$\mathrm{Na}$ análise do conteúdo estomacal de exemplares de jundiá (Rhamdia quelen), coletados na natureza, GUEDES (1980) observou matéria vegetal, insetos, crustáceos, peixes e detritos orgânicos, caracterizando a espécie, quanto ao hábito alimentar, como onívora, com forte preferência por peixes.

No Brasil são escassos os dados nutricionais referentes à criação de larvas e alevinos do jundiá. Entretanto, é de fundamental importância o conhecimento nutricional na primeira fase de vida, visando uma melhor performance das larvas e conseqüentemente a obtenção de alevinos viáveis.

Com a finalidade de aumentar a produção, alguns trabalhos nutricionais foram realizados na Argentina por LUCHINI \& SALAS (1984), no Uruguai por VARELA et al. (1983) e no Brasil por SANTOS et al. (1988) com larvicultura e alevinagem do bagre sul-americano Rhamdia sapo, testando diferentes tipos de alimentos naturais e artificiais, confirmando aceitação de alimento artificial já na primeira fase larval, porém com baixa taxa de sobrevivência.

O objetivo do presente trabalho foi testar diferentes fontes protéicas sobre o desempenho de larvas de jundiá durante as três primeiras semanas de vida.

\section{MATERIAIS E MÉTODOS}

O experimento foi realizado no Setor de Piscicultura, localizado no Departamento de Zootecnia, Centro de Ciências Rurais da Universidade Federal de Santa Maria (UFSM), com duração de 21 dias, no mês de novembro de 1995.

O experimento foi realizado utilizando-se um sistema de re-circulação d'água, termoregulada $\left(22,5 \pm 0,5^{\circ} \mathrm{C}\right)$, aerada $(7,8 \pm 0,5 \mathrm{mg} / \mathrm{l} \mathrm{O})$, acoplado a um biofiltro, descrito por $\mathrm{CHARLON}^{2} \&$ BERGOT (1984). Este sistema possui 16 unidades de criação feitas em fibra de vidro. Cada unidade é constituída de duas bacias, uma externa medindo $38 \times 38 \times 15 \mathrm{~cm}$, e uma interna medindo $33 \times 33 \times 13 \mathrm{~cm}$ que possuem uma capacidade de 8 litros de água. A unidade interna é dotada de uma tela a qual permite a saída d'água. Estes reservatórios foram dotados de abastecimento individual e a vazão utilizada foi de 0,2 1/minuto na primeira semana experimental, $0,41 /$ minuto na segunda semana, e 0,6 1/minuto na terceira semana experimental.

As larvas de jundiá Rhamdia quelen utilizadas foram obtidas através de desova induzida. Após a absorção do saco vitelino, com idade de três dias, as larvas foram distribuídas de dez em dez no sistema de criação numa lotação de 200 larvas por unidade experimental.

Foram testados os valores nutricionais de cinco tratamentos com variação de fontes protéicas de origem animal e vegetal, formulados de modo a serem isoprotéicos $35 \%$ de PB. A quantidade de energia variou entre 2963 e $3287 \mathrm{kcal} \mathrm{ED} / \mathrm{kg}$. A formulação destas dietas foi realizada através do programa de cálculo de rações BRILL, utilizando-se as matérias primas descritas na Tabela 1. Os valores protéicos e energéticos dos alimentos foram descritos por FIALHO (1983) e CHURCH \& POND (1974). Os valores de vitaminas utilizados foram baseados nos requerimentos em colina e biotina para carpa segundo HEPHER (1990). Os valores de minerais seguiram requerimentos para o bagre americano (Ictalurus punctatus) para obter valores de $5 \mathrm{~g}$ de cálcio e $7 \mathrm{~g}$ de fósforo $/ \mathrm{kg}$ de alimento segundo CHO \& SCHELL (1990). O premix vitamínico utilizado era préfabricado, formulado para aves. A quantidade de vitamina C (ácido ascórbico) utilizada foi de 300mg/ $\mathrm{kg}$, recomendado por LI \& LOVELL (1985) para o bagre americano (Ictalurus punctatus).

Para a preparação das rações, os ingredientes foram triturados, separadamente, em moinho e peneirados de modo a se obter uma granulometria menor que $75 \mu$. Após a pesagem, os ingredientes foram misturados para completa homogeneização e certa quantidade de água destilada ( $\pm 30 \%$ ) foi adicionada nos alimentos secos até a mistura adquirir a consistência desejada. Às rações contendo fígado bovino cru, foi adicionada menor quantidade de água. As rações foram, então, passadas em máquina de moer carne e em seguida secas ao ambiente natural (sol) por 8 horas. A temperatura na superfície do alimento esteve em 30 oC. A temperatura média do ar manteve-se em torno de 17,1 oC e a média da umidade relativa do ar foi de $72 \%$. Após a secagem, cada ração foi triturada e peneirada, sendo recuperadas partículas de 100 a $200 \mu, 200$ a $400 \mu$ e 400 a $600 \mu$ para a $1^{a}, 2^{a}$ e $3^{a}$ semanas, respectiva-mente, utilizadas segundo RADÜNZ NETO (1993) para larvas de carpa Cyprinus carpio.

Diariamente o alimento foi oferecido à vontade às larvas a cada meia hora entre 8:00 e 20:00 
horas, formando uma camada que flutuava sobre a superfície da água e a quantidade distribuída foi aumentada com o aumento em tamanho das larvas em estudo. Foi utilizado um fotoperíodo de 12 horas, utilizando-se lâmpadas fluorescentes.

Diariamente foi feita limpeza das bacias, para a retirada de peixes mortos, excrementos e sobra de ração acumulada. A limpeza foi realizada individualmente em cada bacia, através da transferência das larvas com água, através da inclinação da bacia interna, possibilitando desta forma

Tabela 1 - Composiçâo das raçoes experimentais com variação de fonte protéica utilizadas na alimentação de larvas de jundiá Rhamdia quelen no experimento 1 .

\begin{tabular}{|c|c|c|c|c|}
\hline RAÇĀO & $\% \mathrm{~PB}$ & kcal ED/kg & INGREDIENTES & $\%$ \\
\hline \multirow{5}{*}{ TA } & \multirow{5}{*}{35,05} & \multirow{5}{*}{2963,35} & Figado bovino cru (MS) & 28,0 \\
\hline & & & Pó de levedura & 45,0 \\
\hline & & & Farelo de arroz desengordurado & 25,0 \\
\hline & & & Premix vitamínico ${ }^{*}$ & 1,5 \\
\hline & & & Fosfato bicalcico & 0.5 \\
\hline \multirow{6}{*}{ TB } & \multirow{6}{*}{34,64} & \multirow{6}{*}{3155,62} & Farelo de soja & 54,0 \\
\hline & & & Pó de levedura & 34,0 \\
\hline & & & Farelo de arroz desengordurado & 8,0 \\
\hline & & & Óleo de soja & 2,0 \\
\hline & & & Premix vitamínico & 1,5 \\
\hline & & & Fosfato bicálcico & 0,5 \\
\hline \multirow{6}{*}{ TC } & \multirow{6}{*}{35,65} & \multirow{6}{*}{3287,20} & Fígado bovino cru (MS) & 22,0 \\
\hline & & & Farelo de soja & 35,0 \\
\hline & & & Farelo de arroz desengordurado & 35,0 \\
\hline & & & Óleo de soja & 6,0 \\
\hline & & & Premix vitamínico & 1,5 \\
\hline & & & Fosfato bicálcico & 0,5 \\
\hline \multirow{5}{*}{ TD } & \multirow{5}{*}{34,76} & \multirow{5}{*}{3135,94} & Farelo de soja & 70,0 \\
\hline & & & Farelo de arroz desengordurado & 18,0 \\
\hline & & & Farinha de milho & 10,0 \\
\hline & & & Premix vitamínico & 1,5 \\
\hline & & & Fosfato bicálcico & 0,5 \\
\hline \multirow{5}{*}{ TE } & \multirow{5}{*}{35,37} & \multirow{5}{*}{3006,35} & Farinha de carne & 37,0 \\
\hline & & & Farinha de milho & 25,0 \\
\hline & & & Farelo de soja & 26,5 \\
\hline & & & Óleo de soja & 10,0 \\
\hline & & & Premix vitaminico & 1,5 \\
\hline \multicolumn{5}{|c|}{$\begin{array}{l}\text { Composiçåo da mistura vitaminica, scgundo o fabricante (Companhia Minuano d } \\
\text { Alimentos) - Niveis } / \mathrm{kg} \text { do produto: Vit. } A=5.500 .000 \text { UI, Vit. } D_{3}=1.500 .000 \text { UI, Vit } \\
E=12.500 \mathrm{mg} \text {. Vit. } K_{3}=1.750 \mathrm{mg}, \text { Vit. } B_{1}=1500 \mathrm{mg}, \text { Vit. } B_{2}=3.000 \mathrm{mg}, \text { Vit. } B_{6}=1750 \mathrm{mg} \\
\text { Vit. } B_{12}=7000 \mathrm{mcg} \text {, Ácido fólico }=500 \mathrm{mg} \text {, Acido pantotênico }=5.000 \mathrm{mg} \text {, Ácid } \\
\text { nicotínico }=17.500 \mathrm{mg} \text {, Biotina }=75 \mathrm{mg} \text {, Cloreto de colina }=125.000 \mathrm{mg} \text {, DL } \\
\text { Metionina }=300.000 \mathrm{mg} \text { e Antioxidante }=7.500 \mathrm{mg} \text {. }\end{array}$} \\
\hline
\end{tabular}

que o material orgânico ficasse retido nas paredes e permitindo que as larvas sobrenadantes fossem transferidas para o novo reservatório. Após, com o uso de um objeto de sucção, foram retiradas as eventuais sobras de material suspenso na água, possibilitando desta forma uma limpeza mais completa.

Os parâmetros estimados foram:

- Índice de mortalidade, anotado diariamente;

- Comprimento total (CT) e padrão (CP). Estas medidas foram tomadas sobre uma amostra de 10 larvas de cada unidade experimental, a cada 7 dias;

- Peso médio individual (PMI) calculado em função do peso total das larvas de cada unidade experimental, dividido pelo número de peixes sobreviventes no final do experimento.

Biomassa total calculada através do produto do peso médio individual versus sobrevivência final $(\mathrm{P} \times \mathrm{S})$.

Foi utilizado um delineamento inteiramente casualizado com cinco tratamentos e três repetições. Os dados obtidos foram submetidos à análise de variância, ao nível de significância de 5\%, utilizando-se o programa SAS (SAS, 1989), através do sistema operacional CMS. Foi aplicado o teste de Tukey para comparação entre as médias dos tratamentos.

\section{RESULTADOS E DISCUSSÃO}

A percentagem de sobrevivência das larvas nos tratamentos T1, T2, T3, T4 e T5 foram, respectivamente, 61,$17 ; 4,31$; 10,$19 ; 4,50$ e $1,17 \%$, sendo que o T1 apresentou diferença significativa em relação aos demais tratamentos, os quais não diferiram entre si (Tabela 2).

O melhor resultado em sobrevivência $(61,17 \%)$ pode ser observado para o regime T1, à base de fígado bovino (28\%) e levedura (45\%). Este resultado é superior ao encontrado por SANTOS et al. (1988) com $36,57 \%$ de

Ciência Rural, v. 27, n. 2, 1997. 
Tabela 2 - Valores médios (mm)de comprimento total (CT) e padrão (CP), das larvas de jundiá Rhamdia quelen.

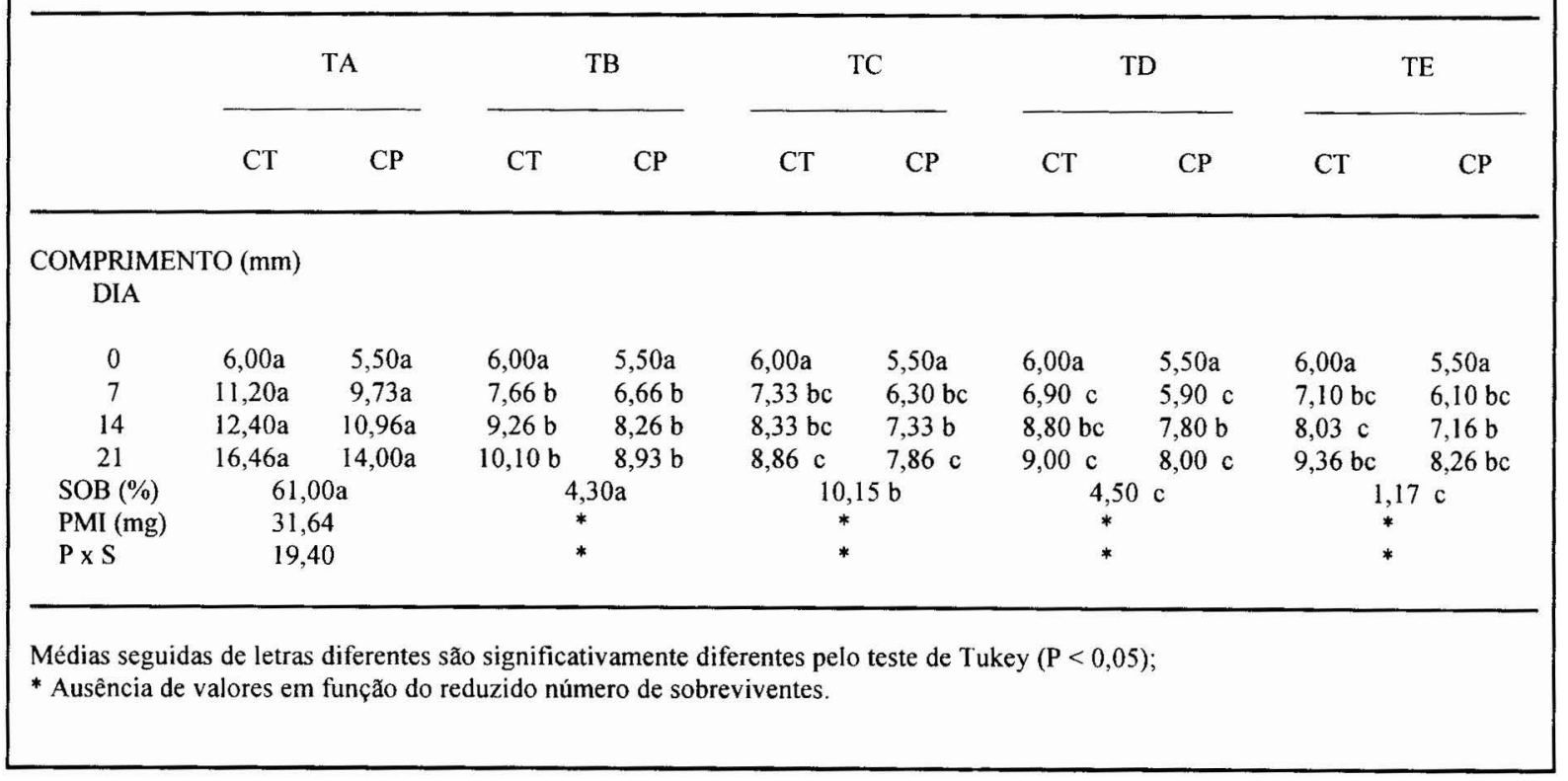

sobrevivência para a fórmula fígado + ração. Por outro lado ALAMI-DURANTE et al. (1991), usando a mistura de fígado bovino e levedura, obtiveram um índice de $95 \%$ de sobrevivência para larvas de Cyprinus carpio, com 21 dias de idade. Uma sobrevivência de $89 \%$ foi obtida por CHARLON \& BERGOT (1984) aos 28 dias para larvas de Cyprinus carpio, utilizando a mesma mistura.

Os regimes à base de farelo de soja apresentaram baixa sobrevivência independentemente das demais fontes protéicas (vegetal ou animal). Segundo ESCAFFRE \& KAUSHIK (1995), o concentrado protéico da soja não pode ser utilizado em dietas para larvas, sem o uso da suplementação do aminoácido sulfurado metionina. Assim sendo, o farelo de soja tostado apresenta, provavelmente, o mesmo problema e nos mostra a necessidade de trabalhos futuros testando-se suplementação em aminoácidos desta fonte protéica vegetal. Segundo BERGOT (1986) não somente a possível deficiência em enzimas digestivas, em particular as proteolíticas, mas uma deficiência na suplementação nutricional em aminoácidos essenciais, vitaminas e minerais resultará em menor desempenho durante a primeira fase de vida das larvas de peixes.

Analisando-se individualmente o comprimento total médio (CTM) das larvas (Tabela 2) constata-se uma diferença significativa no tratamento $\mathrm{T} 1$ já a partir da primeira semana experimental, atingindo 16,46mm em 21 dias. O valor do comprimento total final para o regime $\mathrm{T} 1$, à base de fígado (28\%) e levedura (45\%), é próximo daquele obtido por PIAIA et al. (1995), de 15,20mm aos 21 dias usando a composição fígado (35\%) e levedura (50\%) para larvas de Rhamdia quelen e muito superior ao obtido por SANTOS et al. (1988) para a fórmula fígado mais ração com $40 \%$ de PB apresentando $10 \mathrm{~mm}$ aos 30 dias para larvas de Rhamdia sapo.

$\mathrm{O}$ valor do peso médio individual das larvas foi de $31,64 \mathrm{mg}$ para o $\mathrm{T} 1$, composto por fígado bovino (28\%) e levedura (45\%) e foi semelhante aquele encontrado por PIAIA et al. (1995) para a fórmula 35\% fígado + $50 \%$ levedura, apresentando $33,38 \mathrm{mg}$ aos 21 dias para larvas de Rhamdia quelen, e superior ao obtido por SANTOS et al. (1988) na ordem de $21 \mathrm{mg}$ para a fórmula fígado bovino mais ração para larvas de Rhamdia sapo com 30 dias de idade. Nos demais tratamentos, a sobrevivência e crescimento foram muito baixos não possibilitando a pesagem.

A biomassa final, expressa pelo produto peso versus sobrevivência, obtida para o tratamento T1 foi na ordem de 19,40 . Este dado é inferior se comparado com 30,31 obtido por PIAIA et al. (1995) para larvas de Rhamdia quelen utilizando $50 \%$ de levedura e $35 \%$ de fígado bovino. Estes valores ainda são baixos quando comparados com aqueles obtidos por CHARLON \& BERGOT (1984) e ALAMIDURANTE $\boldsymbol{e t}$ al. (1991) e podem ser melhorados. 
Mas para isto, mais estudos deverão ser realizados com a finalidade de avaliar o efeito do farelo de soja, bem como as exigências em lipídios, vitaminas e minerais para as larvas de jundiá.

\section{CONCLUSÕES}

As larvas de jundiá Rhamdia quelen aceitam alimentos artificiais na troca da alimentação endógena (reservas vitelinas) como única fonte de alimentação.

O regime fígado bovino cru e pó de levedura Saccharomyces cerevisae apresenta-se como o único tratamento viável para ser usado na alimentação durante a primeira fase larval no presente momento.

Mais estudos deverão ser realizados com a finalidade de avaliar o efeito do farelo de soja, bem como as exigências em lipídios, vitaminas e minerais para as larvas de jundiá.

\section{REFERÊNCIAS BIBLIOGRÁFICAS}

ALAMI-DURANTE, H., CHARLON, N., ESCAFFRE, A.M. $\boldsymbol{e}$ al. Supplementation of artificial diets for common carp (Cyprinus carpio) larvae. Aquaculture, n. 93, p. 167-175, 1991.

ANDREATTA, E.R. Influências de diferentes dosagens e intervalos entre aplicações de gonadotrofina coriônica humana (HCG) sobre a reprodução do jundiá, Rhamdia sapo Valenciennes. Santa Maria - RS. 37 p. Dissertação (Mestrado em Zootecnia) - Curso de Pós-graduação em Zootecnia, Universidade Federal de Santa Maria. 1979.

BERGOT, P. Elevage larvaire de la carpe commune (Cyprinus carpio L.): alimentation artificielle. Aquaculture of cyprinides, INRA, Paris, 1986. p. 227-233

CHARLON, N., BERGOT, P. Rearing system for feeding fish larvae on dry diets. Trial with carp (Cyprinus carpio, L.) larvae. Aquaculture, n. 41, p. 1-9, 1984.

CHO, K.W., SCHEL, W.R. The minerals. In: HEPHER, B. Nutrition of pond fishes. Cambridge: Univ. Press, 1990. p. 104-108.

CHURCH, D.C., POND, W.G. Basic animal nutrition and feeding. Church, 1974. 300 p.

ESCAFFRE, A.M., KAUSHIK, S.J. Survival and growth of firstfeeding common carp larvae fed artificial diets containing soybean protein concentrate. Aquaculture, n. 129, p. 251259, 1995 .

FIALHO, E.T. Tabela de composição química e valores energéticos de alimentos para suínos. Concórdia, SC, EMBRAPA-CNPSA, 1983. (Documentos no 6) 23 p.

GUEDES, D.S. Contribuição ao estudo da sistemática e alimentação de jundiás (Rhamdia spp) na região central do Rio Grande do Sul (Pices, Pimelodidae). Santa Maria RS. 100 p. Dissertação (Mestrado em Zootecnia) - Curso de Pós-graduação em Zootecnia, Universidade Federal de Santa Maria. 1980.

HEPHER, B. Nutrition of pond fishes. Cambridge Univ. Press, Inglaterra, 1990. $388 \mathrm{p}$

LUCHINI, L., SALAS, T. Preliminary data on larval survival of South American catfish, Rhamdia sapo. Aquaculture, n. 42, p. $175-177,1984$.

LI, J., LOVELL, R.T. Elevated levels of dietary ascorbic acid increase immune responses in channel catfish. J Nutr, Auburn, v. 115, n. 1, p. $123-131,1985$.

PIAIA, R., ULIANA, O., FILIPETTO, et al. Efeito de diferentes fontes protéicas no crescimento e sobrevivência durante a primeira fase larval do jundia Rhamdia quelen. In: II JORNADA INTEGRADA DE PESQUISA, EXTENSÃO E ENSINO, 1995, Santa Maria, RS. Anais... Pró-Reitoria de Pós-graduação e Pesquisa, 1995. p. 528.

RADÜNZ NETO, J. Détermination des besoins nutritionnels en acides gras essentiels chez les larves de carpe (Cyprinus carpio L.). Tese de Doutorado, 1993. Université de Bordeaux, França. 121 p.

SANTOS, A.B., CHWA, E.Q., THOMPSON, D.M. Produção e criação de alevinos de Rhamdia sapo Valenciennes, 1840. In: VI SIMPÓSIO LATINOAMERICANO E V SIMPÓSIO BRASILEIRO DE AQUICULTURA, 1988, Florianópolis, SC. Anais... Florianópolis, 1988. p. 615-620.

SAS - Statistical Analysis System. User's Guide. Version 6, SAS INSTITUTE INC. 4. ed. North Caroline: SAS INSTITUTE INC>, 1989. 846 p.

VARELA, Z., FABIANO, G., FISCHER, K. Cria de larvas de bagre negro (Rhamdia sapo, Valenciennes) en el laboratorio. Resumenes comun. Ciências naturales, INSN, Montevideo. Uruguai. 1983. n. 3, p. 117-118. 